\title{
Efficacy of paracetamol on patent ductus arteriosus closure may be dose dependent: evidence from human and murine studies
}

\author{
Afif El-Khuffash', Amish Jain², David Corcoran', Prakesh S. Shah², Christopher W. Hooper ${ }^{3}$, Naoko Brown ${ }^{3}$, Stanley D. Poole, \\ Elaine L. Shelton ${ }^{3}$, Ginger L. Milne ${ }^{4}$, Jeff Reese ${ }^{3}$ and Patrick J. McNamara ${ }^{5,6}$
}

BACKGROUND: We evaluated the clinical effectiveness of variable courses of paracetamol on patent ductus arteriosus (PDA) closure and examined its effect on the in vitro term and preterm murine ductus arteriosus (DA).

METHODS: Neonates received one of the following three paracetamol regimens: short course of oral paracetamol (SCOP), long course of oral paracetamol (LCOP), and intravenous paracetamol (IVP) for 2-6 d. Pressure myography was used to examine changes in vasomotor tone of the preterm and term mouse DA in response to paracetamol or indomethacin. Their effect on prostaglandin synthesis by DA explants was measured by mass spectroscopy.

RESULTS: Twenty-one preterm infants were included. No changes in PDA hemodynamics were seen in SCOP infants $(n=5)$. The PDA became less significant and eventually closed in six LCOP infants $(n=7)$. PDA closure was achieved in eight IVP infants $(n=9)$. On pressure myograph, paracetamol induced a concentration-dependent constriction of the term mouse DA, up to $30 \%$ of baseline $(P<0.01)$, but required $>1 \mu \mathrm{mol} / \mathrm{l}$. Indomethacin induced greater DA constriction and suppression of prostaglandin synthesis $(P<0.05)$.

CONCLUSION: The clinical efficacy of paracetamol on PDA closure may depend on the duration of treatment and the mode of administration. Paracetamol is less potent than indomethacin for constriction of the mouse DA in vitro.

$T$ here is a need to explore alternatives to current therapeutic approaches of patent ductus arteriosus (PDA) in preterm infants for several reasons. First, medical closure of the PDA is limited to nonselective nonsteroidal anti-inflammatory drugs (NSAIDs), namely indomethacin and ibuprofen, but these only achieve a closure rate of $70-80 \%$. Second, there remain concerns regarding the safety of NSAIDs. Third, NSAID drugs are contraindicated in infants with feeding intolerance, necrotizing enterocolitis, intestinal perforation, intraventricular hemorrhage, concomitant use of corticosteroids, and severe hyperbilirubinemia (1). There is an increasing interest in the use of paracetamol for PDA closure in preterm infants with the recent publication of several case reports (2-8). However, the enthusiasm to proceed with interventional trials needs to be tempered as there remains a paucity of pharmacodynamic data on this treatment in preterm infants. The dose-response relationship between paracetamol and PDA closure needs prospective evaluation.

Case reports suggest that paracetamol may be an effective agent in inducing ductal closure and is probably not associated with serious side effects. The vasoconstrictive effect of paracetamol on ductal tissue is achieved through inhibition of the peroxidase moiety, thereby inhibiting prostaglandin production (7). Oral and intravenous (i.v.) paracetamol have demonstrated efficacy in PDA closure in a variety of situations, particularly when conventional NSAIDS are either contraindicated, or have failed to achieve PDA closure $(2,3,5,6)$. Those studies however, used paracetamol in a heterogeneous group of infants with limited echocardiography data on the characteristics of the PDA. In this study, we retrospectively examined the effectiveness of three distinct clinical regimes of paracetamol administration in preterm infants, which provide escalating drug levels (phase I). In addition, we performed an in vitro evaluation of the dose-responsiveness of paracetamol in the term and preterm murine ductus arteriosus (DA) (phase II).

\section{RESULTS}

\section{Human Study}

A total of 21 infants were included in the study; specifically, 5 infants received a short course of oral paracetamol (SCOP), 7 received a long course of oral paracetamol (LCOP), and 9 infants received a course of intravenous paracetamol (IVP) (Table 1). The PDA remained open in all neonates who received SCOP. There was neither clinical improvement nor change in the echocardiography markers of hemodynamic significance following treatment (Table 2). All infants eventually required PDA ligation. Seven infants received a LCOP (LCOP group,

\footnotetext{
'Department of Pediatrics, The Rotunda Hospital, Dublin, Ireland; ${ }^{2}$ Department of Pediatrics, Mount Sinai Hospital, Toronto, Ontario, Canada; ${ }^{3}$ Division of Neonatology, Department of Pediatrics, Vanderbilt University Medical Center, Nashville, Tennessee; ${ }^{4}$ Division of Clinical Pharmacology, Department of Medicine, Vanderbilt University School of Medicine, Nashville, Tennessee; ${ }^{5}$ Department of Neonatology, The Hospital for Sick Children, Toronto, Ontario, Canada; ${ }^{6}$ Department of Physiology and Experimental Medicine, Hospital for Sick Children, Toronto, Ontario, Canada. Correspondence: Patrick J. McNamara (patrick.mcnamara@sickkids.ca) 


\section{Paracetamol and PDA closure $\quad$ Articles}

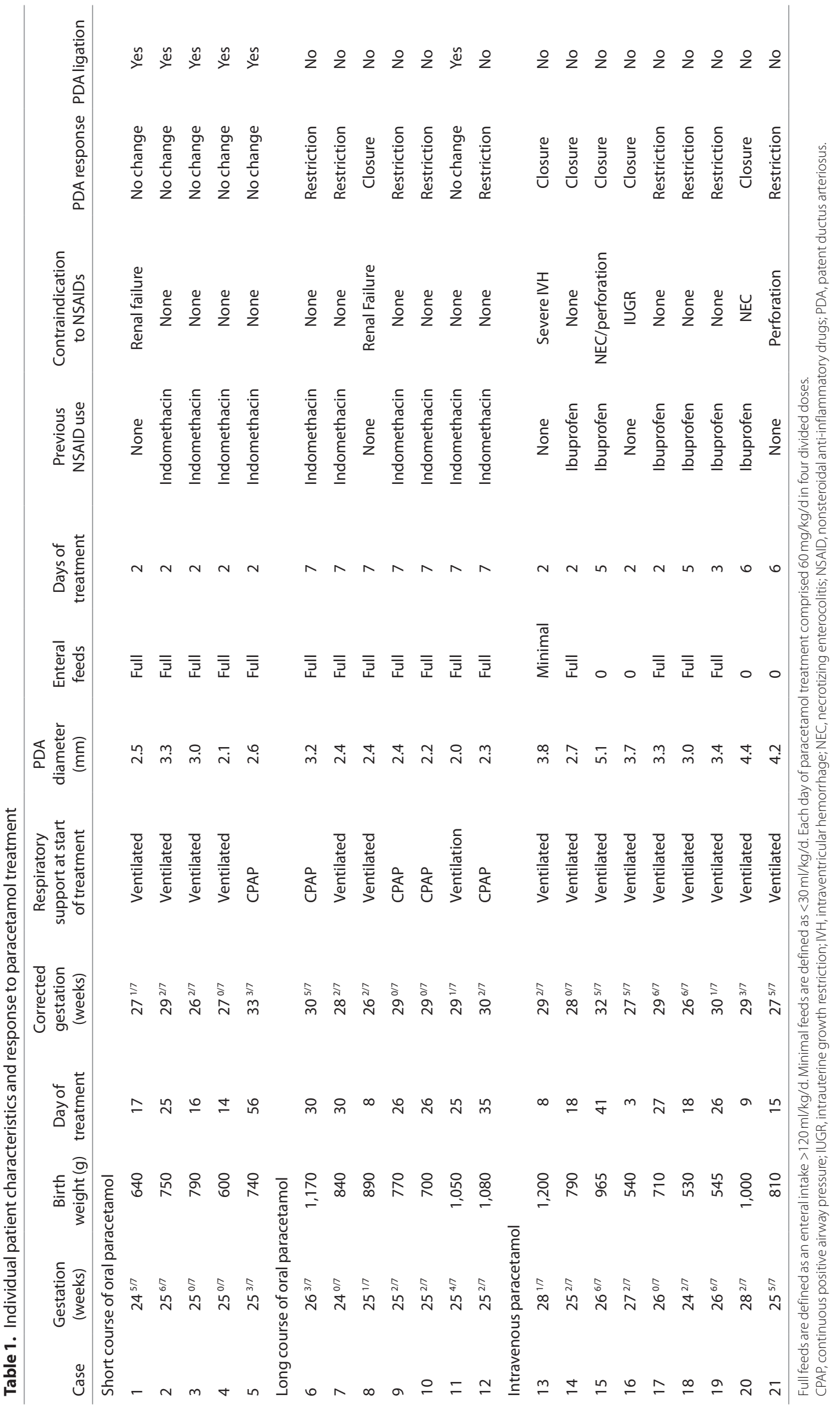


Table 1). Following a 7-d course, PDA closure was achieved in one patient and there was a reduction of ductal diameter and an improvement of the echocardiography markers of PDA significance in five infants (Table 2). All six infants demonstrated clinical improvement and were successfully weaned from respiratory support. There was no response to treatment in one infant who required PDA ligation.

Nine infants received IVP treatment (IVP group). Of these, five achieved immediate PDA closure and three infants demonstrated a significant reduction of PDA diameter (Table 2). Subsequent PDA closure was achieved in the three infants prior to discharge without any need for further intervention.
The remaining infant had a nonsignificant PDA on discharge. Two infants died during their hospital stay due to unrelated causes (pulmonary hypoplasia and cystic periventricular leukomalacia). None of the deaths occurred during paracetamol therapy. None of the infants in the cohort had elevated liver enzyme or developed liver toxicity. None of the PDAs successfully closed following LCOP or IVP reopened after treatment.

\section{In Vitro Study}

The isolated mouse DA is more sensitive to indomethacin than paracetamol. Exposure to paracetamol did not produce a significant change in the diameter of the ex vivo preterm

Table 2. Echocardiography characteristics before and after treatment of the groups

\begin{tabular}{|c|c|c|c|c|c|c|c|c|c|}
\hline & \multicolumn{3}{|c|}{ Short course of oral paracetamol } & \multicolumn{3}{|c|}{ Long course of oral paracetamol } & \multicolumn{3}{|c|}{ Intravenous paracetamol } \\
\hline & Pre & Post & $P$ & Pre & Post & $P$ & Pre & Post & $P$ \\
\hline PDA diameter (mm) & $2.8(2.6-3.0)$ & $3.1(3.0-3.1)$ & 0.04 & $2.4(2.2-2.5)$ & $1.4(1.0-1.8)$ & 0.03 & $3.7(3.2-4.3)$ & $0(0-1.1)$ & $<0.01$ \\
\hline IVRT (msec) & $36(34-37)$ & $36(34-37)$ & 0.29 & $39(35-41)$ & $52(47-57)$ & 0.08 & $44(37-57)$ & $48(43-54)$ & 0.67 \\
\hline $\operatorname{LVO}(\mathrm{ml} / \mathrm{min} / \mathrm{kg})$ & $328(305-385)$ & $358(334-555)$ & 0.27 & $435(395-533)$ & $321(246-350)$ & 0.03 & $271(238-390)$ & $192(184-224)$ & 0.03 \\
\hline
\end{tabular}

Data are presented as medians (interquartile range).

IVRT, isovolumic relaxation time; LVO, left ventricular output; LVEDD, left ventricular end diastolic velocity; PDA, patent ductus arteriosus.
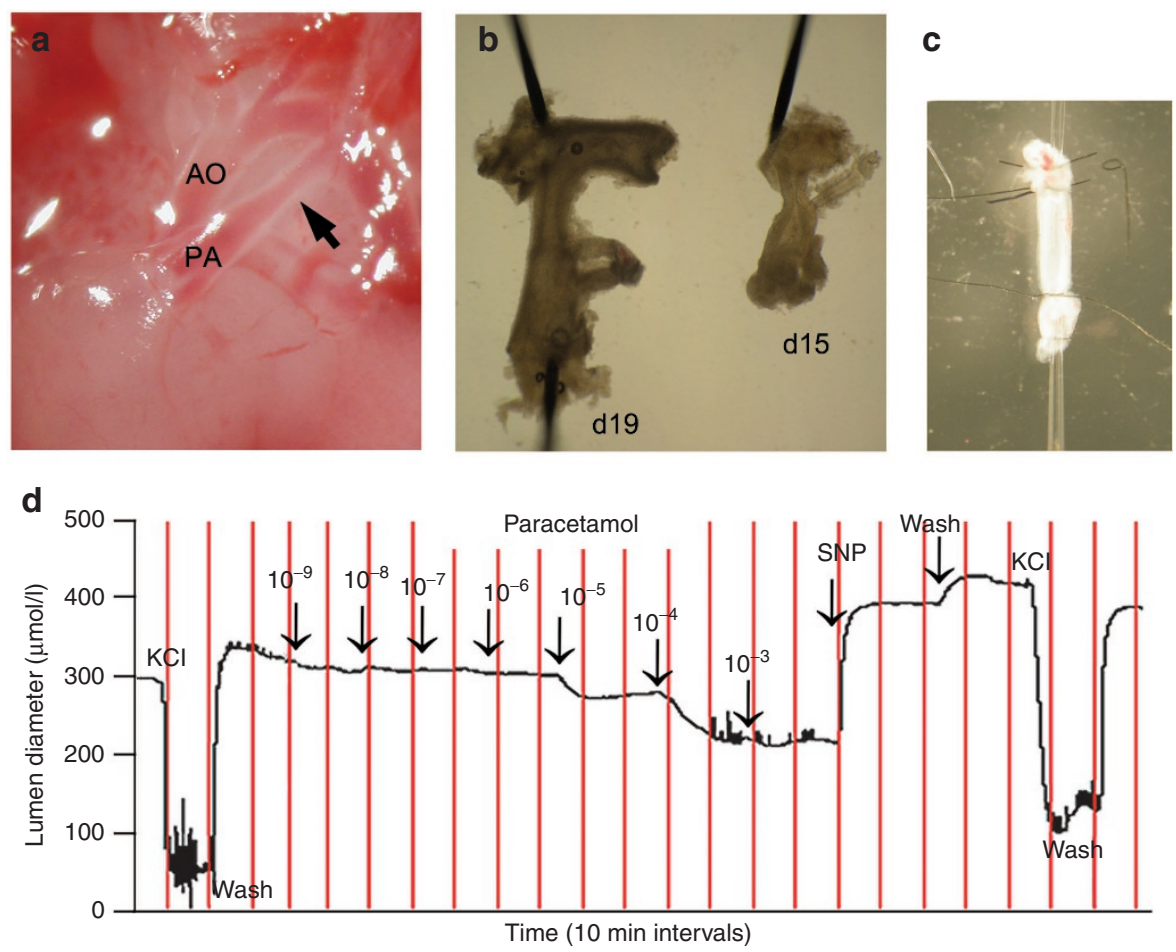

Figure 1. Paracetamol-induced constriction of the ex vivo ductus arteriosus. The ductus arteriosus (arrow) of fetal mice (a) was sharply excised from surrounding tissues. The ductus of term (day 19) and preterm (day 15) fetuses were removed along with a vascular segment extending from the base of the pulmonary artery to the transverse aortic arch (b) (shown with $100 \mu \mathrm{m}$ dissecting pins). This vascular bloc was mounted on glass pipette tips and secured by tying back the branch pulmonary arteries and the aortic arch, in order to isolate the entire length of the ductus for myography studies (c). Pressure myography was performed to study ductus tone and examine drug-induced changes in lumen diameter (d). After pressurization and equilibration, mounted vessels were briefly exposed to $50 \mathrm{mmol} / \mathrm{K} \mathrm{KCl}$ to verify contractile potential, then allowed to return to baseline tone. Cumulative exposure to increasing paracetamol demonstrated concentration-dependent constriction of the day 19 ductus (d). Constricted vessels were then exposed to sodium nitroprusside, a potent nitric oxide donor, to document vasodilatory capacity. Terminal exposure to $\mathrm{KCl}$ ensured viability of the preparation at the end of each experiment. 
DA. Indomethacin caused a small but significant constriction of the ductus with increasing concentration (Figure 2a). In contrast, indomethacin produced marked constriction of the isolated mouse ductus at term gestation, with complete closure of the vessel lumen at the highest concentrations studied (Figure 2b). Paracetamol also caused significant concentration-dependent constriction of the term ductus. The magnitude of paracetamol-induced constriction was less than half of indomethacin-induced constriction at each concentration. Ex vivo lumen closure was not observed in paracetamol treated vessels.

Indomethacin inhibits ductus-specific prostaglandin production. Due to the limited quantity of preterm ductus tissue and because isolated preterm vessels had only modest response to inhibitors (Figure 2a), only the excised ductus of term gestation mice was assayed for prostaglandin synthesis. We observed significant reduction in 6-keto prostaglandin $\mathrm{F}_{1 \alpha}\left(\mathrm{PGF}_{1 \alpha}\right)$, the stable metabolite of prostacyclin $\left(\mathrm{PGI}_{2}\right)$, and prostaglandin $\mathrm{E}_{2}$ $\left(\mathrm{PGE}_{2}\right)$ in response to indomethacin treatment (Figure 3). A reduced trend in prostaglandin (PG) synthesis was noted in paracetamol-treated explants, but did not reach significance in this particular assay. Thromboxane $\mathrm{B}_{2}\left(\mathrm{TxB}_{2}\right)$ and prostaglandin $\mathrm{D}_{2}\left(\mathrm{PGD}_{2}\right)$ levels were below the detection limits of the
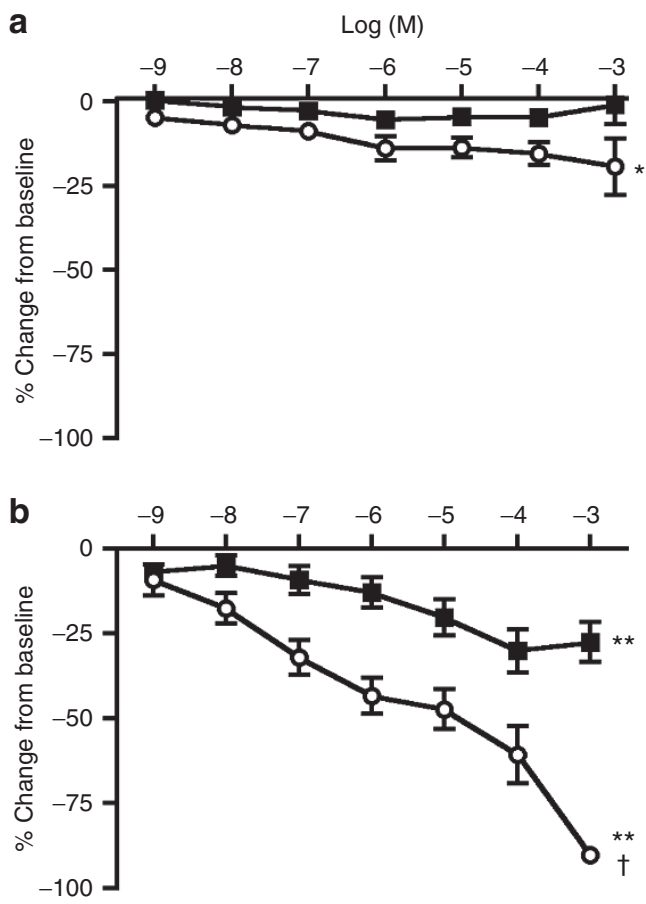

Figure 2. Response of the ex vivo ductus arteriosus to paracetamol and indomethacin. The isolated ductus of preterm mice (a) displayed limited response to increasing concentrations of paracetamol (black squares, $n=$ 12) whereas indomethacin (white circles, $n=12$ ) induced a modest, significant constriction $(* P<0.05)$. The isolated ductus of term gestation mice (b) showed significant concentration-dependent constriction in response to either drug $\left({ }^{* *} P<0.01\right)$. Indomethacin (white circles, $n=9$ ) was more effective than paracetamol (black squares, $n=9$ ) at term gestation $\left({ }^{+} P<\right.$ $0.001)$. Each drug was more potent at term than preterm gestation $(P<$ 0.01). Mean \pm SEM. instrument; interfering substances with similar $\mathrm{m} / z$ characteristics prevented accurate interpretation of $\mathrm{PGF}_{2 \alpha}$ results.

\section{DISCUSSION}

In this study, we demonstrated that the responsiveness of the DA to paracetamol may depend on the method of administration, duration of treatment, and the dose of the drug. The response to paracetamol treatment was highly variable, ranging from no response in infants receiving SCOP, to near-complete closure in the majority of patients who received IVP, which suggests that a critical paracetamol level is required to achieve maximal therapeutic effect. The complete ineffectiveness of SCOP is in contrast to other recent reports assessing the efficacy of oral paracetamol on ductal closure $(2,4,6,8)$. There were, however, differences in the treatment cohort that may explain the discordance. Unlike our cohort, neonates had a higher gestational age at birth (26 up to $36 \mathrm{vs.} 25 \mathrm{wk}$ ), PDA diameter was smaller (1.5-2.0 vs. $2.0 \mathrm{~mm}$ and greater), and treatment was initiated at an earlier postnatal age (5-9 vs. 17 d). In addition, no echocardiography information was available to appraise the hemodynamic impact of the PDA. It is possible that the PDA was of borderline hemodynamic significance and may have closed spontaneously. Our experience with a longer course of oral paracetamol was more positive with avoidance of the need for PDA ligation in all but one patient. This may relate to achieving a higher serum drug level or may be a function of more prolonged exposure to the biological effects of
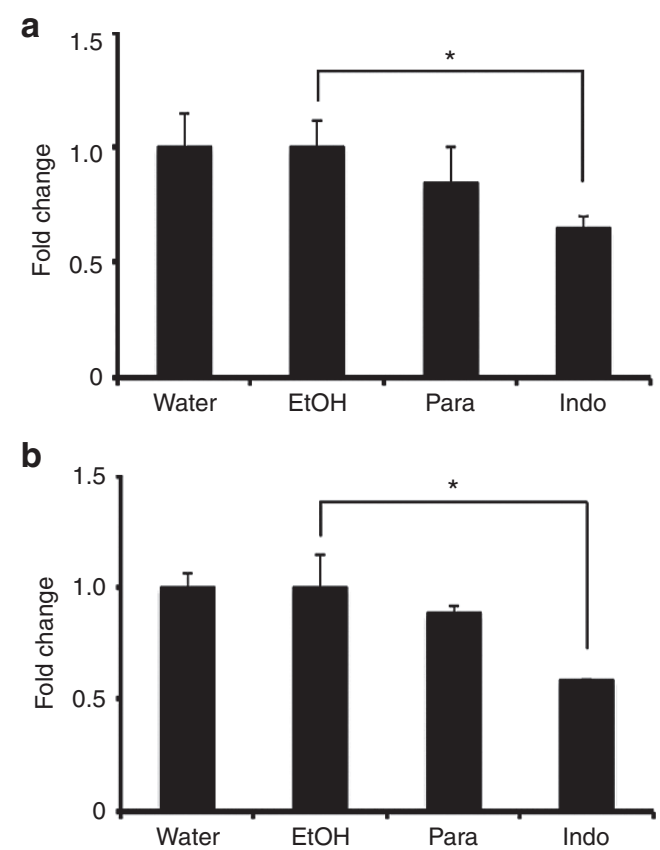

Figure 3. Inhibition of ductus arteriosus prostaglandin synthesis. Freshly isolated term gestation ductus explants were incubated in the presence of drug or the appropriate vehicle. Prostaglandin synthetic activity was measured by the formation of 6-keto PGF $1 \alpha$, the stable metabolite of prostacyclin (PGI2) (a), or PGE2 (b) after exposure to exogenous 2 umol/I arachidonic acid for $40 \mathrm{~min}$. Vessels treated with paracetamol (Para) had insignificant reduction in prostaglandin synthesis compared to vehicle (water). Indomethacin-treated vessels (Indo) produced significantly less PGI2 and PGE2 compared to controls (ethanol). ${ }^{*} P<0.01$. 
paracetamol. Oncel et al. (3) achieved 100\% closure rate in 10 infants who received IVP. Although gestational age and weight at birth were comparable, advanced age at treatment (median of 18 vs. $6 \mathrm{~d}$ ) and larger PDA diameter (3.7 (3.2-4.3) vs. 2.0 $(1.8-2.4))$ in our cohort may account for the discrepancy in treatment success rate between the two studies. Paracetamol serum levels after $48 \mathrm{~h}$ of an i.v. course are higher than those achieved after $48 \mathrm{~h}$ of an oral course of $60 \mathrm{mg} / \mathrm{kg} / \mathrm{d}$ as reported by Yurttutan et al. (6) (15.5 (10-26) vs. $13 \mu \mathrm{g} / \mathrm{ml}(5-18))$. The benefits of IVP have not been uniform. Roofthooft et al. (9) reported giving paracetamol at a dose of $60 \mathrm{mg} / \mathrm{kg} / \mathrm{d}$ to 10 infants ( 9 with i.v. and 1 with oral paracetamol) with a median (range) gestation of $25^{1 / 7}\left(23^{6 / 7}-26^{6 / 7}\right)$ at a median age of $22 \mathrm{~d}$. PDA failed to close in seven of those infants with all needing ligation. PDA closure was achieved in only one infant, with one infant exhibiting PDA restriction and another infant died from gastrointestinal problems. None of the infants developed liver toxicity. Similarly, another case series of three infants reported failure of PDA closure in all patients following IV paracetamol $(15 \mathrm{mg} / \mathrm{kg}$ every $6 \mathrm{~h}$ of unspecified duration), necessitating surgical ligation. Two infants developed transient raised liver enzymes (10). More recently in a randomized controlled trial, Oncel et al. compared the efficacy of oral paracetamol (at a dose of $15 \mathrm{mg} / \mathrm{kg}$ every $6 \mathrm{~h}$ for $3 \mathrm{~d}$ ) with that of oral ibuprofen (at a dose of $10 \mathrm{mg} / \mathrm{kg}$ followed by two doses of $5 \mathrm{mg} / \mathrm{kg} 24 \mathrm{~h}$ apart) in a group of 80 preterm infants less than $1,250 \mathrm{~g}$. The treatment was instituted between 48 and $96 \mathrm{~h}$ of life. The group found that paracetamol achieved similar PDA closure rates to ibuprofen (72.5 vs. $77.5 \%$ ) with no significant differences in reopening rates (11). This study suggests that the timing of treatment is also an important consideration as early PDAs may be more responsive to paracetamol than the ones treated beyond the second week of life.

In the animal experiment, unlike indomethacin, paracetamol did not have an ex vivo constricting effect on the preterm ductus, and vessels treated with paracetamol had insignificant reduction in prostaglandin synthesis compared to vehicle (water). Indomethacin-treated vessels produced significantly less $\mathrm{PGI}_{2}$ and $\mathrm{PGE}_{2}$ compared to controls (ethanol). We previously showed that the preterm mouse DA was less affected by $10^{-5} \mathrm{~mol} / \mathrm{l}$ indomethacin than the term gestation DA (12). The current study examined the ductus response to an extended range of indomethacin concentrations and demonstrates a marked upregulation in sensitivity of the ductus to prostaglandin inhibition with advancing gestation. This finding is in agreement with previous clinical reports $(13,14)$ and observations in other animal species (15). Momma et al. (16) also demonstrated that indomethacin (when administered to the maternal rat) possesses a more potent DA-constricting effect in fetal rats when compared to paracetamol. Paracetamol, however, also possessed a significant but milder constrictive effect. The results of the clinical observation by Roofthooft (9) highlighted above support the finding of our animal study. The difference in response between the human and mouse preterm ductus may represent different expression of the peroxidase moiety of prostaglandin $\mathrm{H}_{2}$ Synthetase enzyme responsible for metabolizing arachidonic acid (7). The differences may also relate to the fact that the majority of human neonates who received paracetamol were previously treated with NSAIDs, which may modulate the responsiveness of ductal tissue through mechanisms that have not been delineated. It was not possible to mimic the human situation using the in vitro experimental design.

$\mathrm{PGE}_{2}$ is the most important factor in the regulation of DA tone during fetal DA development. It is generated through the combined actions of prostaglandin $\mathrm{H}$ synthase-1/-2 (PGHS$1 /-2$ ) and microsomal PGE synthase enzymes on arachidonic acid. PGE $_{2}$ acts on $G$ protein-coupled E-prostanoid receptors causing vasodilation of ductal tissue (17). The inhibition of PGHS-1 leads to reduced $\mathrm{PGE}_{2}$ levels and ductal constriction (18). Current practice exploits this mechanism by the use of nonselective PGHS inhibitors such as indomethacin and ibuprofen to close ducts postnatally $(19,20)$. Paracetamol is also thought to be a potent PGHS inhibitor and reduces the levels of $\mathrm{PGE}_{2}$. The paracetamol trend of lowering $\mathrm{PGE}_{2}$ levels in our study further supports this mechanism. However, there may be a graded inhibition effect, which is related to gestation. Both clinical and animal evidence suggest that the inhibitory effect of paracetamol on $\mathrm{PGE}_{2}$ is not present at lower gestations.

Our study was limited by the small number of infants and the lack of paracetamol drug levels in the clinical study. As a result, we could not demonstrate that the escalating dosing regimen described in our infant cohort translated into an escalating drug level. We based this assumption on the graded clinical response to the varying regimens. In addition, the ex vivo effect of paracetamol on preterm and term mice DAs may not mirror the in vivo effect in humans, and the result of this needs to interpret with caution.

In conclusion, the routine use of paracetamol for PDA closure in preterm infants cannot be recommended until randomized controlled trials of its efficacy are completed. Those RCTs should be supported by robust pharmacokinetic data designed to determine the optimal dosing regimen, duration of treatment, and mode of administration. The safety of the use of paracetamol to close PDAs in preterm infants also warrants further investigation.

\section{METHODS}

Human Study

Study setting. This was a retrospective review of all infants who received paracetamol for PDA closure in two tertiary neonatal intensive-care units between January 2012 and June 2013: Mount Sinai Hospital, and The Rotunda Maternity Hospital, Dublin, Ireland. One center (Mount Sinai Hospital) administered either SCOP of $15 \mathrm{mg} /$ $\mathrm{kg}$ every $6 \mathrm{~h}$ for $48 \mathrm{~h}$ or LCOP of $15 \mathrm{mg} / \mathrm{kg}$ every $6 \mathrm{~h}$ for $7 \mathrm{~d}$ (tylenol oral suspension liquid $160 \mathrm{mg} / 5 \mathrm{ml}$, Johnson \& Johnson, Toronto, Ontario, Canada). This was done on an ad hoc basis due to the various reports of the differing regimens at the time. Neonates at the second center (Rotunda) received IVP of $15 \mathrm{mg} / \mathrm{kg}$ every $6 \mathrm{~h}$ for a minimum of $48 \mathrm{~h}$ until PDA closure was confirmed on echocardiography or up to a maximum of $6 \mathrm{~d}$ (paracetamol $10 \mathrm{mg} / \mathrm{ml}$ solution for infusion, Fresenius Kabi, Cheshire, UK). In both centers, the decision to administer paracetamol treatment to neonates with a hemodynamically significant PDA was either after failure of two courses of either ibuprofen or indomethacin or if there were contraindications to medical treatment. Liver enzymes were measured before and after 
treatment. Paracetamol was only commenced if liver function tests were normal.

Clinical and echocardiography data. The following clinical information was collected for every infant enrolled: gestation and birth weight; previous use of NSAID; contraindications to NSAID use; age and weight at paracetamol treatment; duration of paracetamol treatment; and reason for PDA treatment. Treatment of the PDA was at the discretion of the attending neonatologist. Clinical outcomes within 7 $\mathrm{d}$ of treatment were also collected and included PDA ligation, weaning of ventilator or continuous positive airway pressure support, and death.

In both centers, echocardiography assessment of PDA significance was performed before and after paracetamol treatment using GE Vivid I (GE Medical, Milwaukee, WI), or Phillips HD15 Ultrasound system (Andover, MA). PDA treatment with paracetamol was commenced if there was clinical concern and echocardiography evidence of a large PDA ( $>2.0 \mathrm{~mm}$ ) accompanied by echocardiography evidence of pulmonary over circulation or systemic hypoperfusion (21). The following echocardiography parameters were collected before and after treatment: PDA diameter (measured in 2D at the pulmonary end) and shunt direction, mean pressure gradient across the PDA, and markers of pulmonary over-circulation (left atrium: aortic (LA:Ao) ratio; isovolumic relaxation time; left ventricular output and left ventricular end diastolic velocity).

The institutional ethics committees of Mount Sinai Hospital and The Rotunda Hospital approved the retrospective clinical review.

\section{In Vitro Study}

Animals and tissues. Due to the limited availability and viability of human ductus tissues, the response of the ex vivo term and preterm mouse DA to indomethacin and paracetamol was examined. Experiments were conducted in accordance with National Institutes of Health animal care standards and were approved by the Institutional Animal Care and Use Committee at Vanderbilt University Medical Centre. Adult female CD1 mice (Charles River, Raleigh, NC) were bred with fertile males of the same strain to produce timed pregnancies. The morning of finding a vaginal plug was considered day 1 of pregnancy. Preterm (day 15) and term (day 19) gestation DA were surgically isolated and either mounted in microvessel perfusion chambers as previously described (12), or plated for drug inhibition studies.

Pressure myography. Pressure myography was used to directly study vasomotor tone of the isolated DA. Myography chambers were placed on inverted microscopes equipped with a digital image capture system (IonOptix, Burlington, VT) to record intraluminal diameter. Vessels were studied in deoxygenated $\left(95 \% \mathrm{~N}_{2}, 5 \% \mathrm{CO}_{2}\right)$ Krebs buffer that was modified (in mmol/l: $109 \mathrm{NaCl}, 34 \mathrm{NaHCO}_{3}, 4.7 \mathrm{KCl}, 0.9$ $\mathrm{MgSO}_{4}, 1.0 \mathrm{KH}_{2} \mathrm{PO}_{4}, 11.1$ dextrose, and $2.5 \mathrm{CaCl}_{2}$ ) to maintain a stable $\mathrm{pH}^{4}(7.30-7.35)$ and relative hypoxia in the vessel bath (dissolved oxygen content $=1.5-1.8 \%$; measured $\mathrm{PaO}_{2}=38-45$ Torr). Mounted vessels were pressurized using a column of Krebs buffer and allowed to equilibrate, after which the pressure was increased in a stepwise manner to approximate mean arterial pressure $(6 \mathrm{mmHg}$, preterm; $20 \mathrm{mmHg}$, term). Vessels were then challenged with two doses of 50 $\mathrm{mmol} / \mathrm{l} \mathrm{KCl}$ in Krebs buffer to test vessel reactivity and to determine maximum constriction values. Vessels that failed to constrict were excluded from further study. After wash out with Krebs buffer, vessels were exposed to increasing concentrations $\left(10^{-9}\right.$ to $\left.10^{-3} \mathrm{~mol} / \mathrm{l}\right)$ of paracetamol or indomethacin in the perfusion bath. Changes in vessel diameter were continuously monitored by video recording; lumen diameter was plotted in real-time to determine the concentration-specific effects of each drug. Following each drug dose, vessel diameters were allowed to plateau (10-20 min) before addition of the next dose. At the end of each drug study, the nitric oxide donor, sodium nitroprusside (SNP) was added to demonstrate the vasodilatory capacity of the ductus after drug-induced vasoconstriction; then compounds were washed off and vessels returned to resting baseline tone (Figure 1). After the final wash out, vessels were challenged with $50 \mathrm{mmol} / \mathrm{l} \mathrm{KCl}$ at the completion of each study to demonstrate viability of the vessel preparation. Paracetamol was prepared in water; indomethacin was dissolved in ethanol but did not exceed $0.1 \%$ in the final bath concentration.

Measurement of prostaglandins. The ductus of term fetal mice (day $19, n=3$ litters) were sharply excised from surrounding tissues, split open along the longitudinal axis, and placed in a 96-well plate containing serum-free Dulbecco's modified Eagle's medium media $+1 \%$ penicillin-streptomycin (three vessels per well). Vessels were then exposed to paracetamol $\left(10^{-4} \mathrm{~mol} / \mathrm{l}\right)$, indomethacin $\left(5.6 \times 10^{-6} \mathrm{~mol} / \mathrm{l}\right)$, or vehicle controls (water or ethanol, respectively) for $40 \mathrm{~min}$ at 37 ${ }^{\circ} \mathrm{C}$, after which the conditioned media was collected for analysis. PG, including $\mathrm{PGE}_{2}, \mathrm{PGD}_{2}, \mathrm{PGF}_{2,}, \mathrm{TxB}_{2}$ and the prostacylin metabolite 6-keto-PGF ${ }_{1 \alpha}$, were measured in the conditioned media by a stable isotope dilution assay utilizing gas chromatography/negative ion chemical ionization-mass spectrometry as previously described (22-25).

Statistical analysis. Continuous data were presented as medians and interquartile ranges, and categorical data as absolute values and percentages. Independent data were compared using Mann-Whitney $U$-test, and paired data were compared using Wilcoxon signed-rank test. Multiple groups were compared using the Kruskal-Wallis test. Clinical variables were not compared statistically. For the animal data, individual drug responses were analyzed by repeated measures ANOVA; interdrug comparison was analyzed using two-way ANOVA. Post hoc analysis (Tukey) was performed for studies that were significant. We considered a $P$ value of $<0.05$ as significant. We used SPSS (version 20.0) to perform the analysis.

\section{REFERENCES}

1. Clyman RI, Couto J, Murphy GM. Patent ductus arteriosus: are current neonatal treatment options better or worse than no treatment at all? Semin Perinatol 2012;36:123-9.

2. Hammerman C, Bin-Nun A, Markovitch E, Schimmel MS, Kaplan M, Fink D. Ductal closure with paracetamol: a surprising new approach to patent ductus arteriosus treatment. Pediatrics 2011;128:e1618-21.

3. Oncel MY, Yurttutan S, Degirmencioglu H, et al. Intravenous paracetamol treatment in the management of patent ductus arteriosus in extremely low birth weight infants. Neonatology 2013;103:166-9.

4. Oncel MY, Yurttutan S, Uras N, et al. An alternative drug (paracetamol) in the management of patent ductus arteriosus in ibuprofen-resistant or contraindicated preterm infants. Arch Dis Child Fetal Neonatal Ed 2013;98:F94.

5. Tekgunduz KS, Ceviz N, Demirelli Y, et al. Intravenous paracetamol for patent ductus arteriosus in premature infants - a lower dose is also effective. Concerning the article by M.Y. Oncel et al: Intravenous paracetamol treatment in the management of patent ductus arteriosus in extremely low birth weight infants. Neonatology 2013;104:6-7.

6. Yurttutan S, Oncel MY, Arayicı S, et al. A different first-choice drug in the medical management of patent ductus arteriosus: oral paracetamol. J Matern Fetal Neonatal Med 2013;26:825-7.

7. Allegaert K, Anderson B, Simons S, van Overmeire B. Paracetamol to induce ductus arteriosus closure: is it valid? Arch Dis Child 2013;98:462-6.

8. Ozdemir OM, Doğan M, Küçüktaşçı K, Ergin H, Sahin O. Paracetamol therapy for patent ductus arteriosus in premature infants: a chance before surgical ligation. Pediatr Cardiol 2014;35:276-9.

9. Roofthooft DW, van Beynum IM, Helbing WA, Reiss IK, Simons SH. Paracetamol for ductus arteriosus closure: not always a success story. Concerning the article by M.Y. Oncel et al: intravenous paracetamol treatment in the management of patent ductus arteriosus in extremely low birth weight infants. Neonatology 2013;104:170.

10. Alan S, Kahvecioglu D, Erdeve O, Atasay B, Arsan S. Is paracetamol a useful treatment for ibuprofen-resistant patent ductus arteriosus? Concerning the article by M.Y. Oncel et al: intravenous paracetamol treatment in the management of patent ductus arteriosus in extremely low birth weight infants. Neonatology 2013;104:168-9.

11. Reese J, O'Mara PW, Poole SD, et al. Regulation of the fetal mouse ductus arteriosus is dependent on interaction of nitric oxide and COX enzymes in the ductal wall. Prostaglandins Other Lipid Mediat 2009;88:89-96. 
12. Oncel MY, Yurttutan S, Erdeve O, et al. Oral paracetamol versus oral ibuprofen in the management of patent ductus arteriosus in preterm infants: a randomized controlled trial. J Pediatr 2014;164:510-4.e1.

13. Moise KJ Jr. Effect of advancing gestational age on the frequency of fetal ductal constriction in association with maternal indomethacin use. Am J Obstet Gynecol 1993;168:1350-3.

14. Vermillion ST, Scardo JA, Lashus AG, Wiles HB. The effect of indomethacin tocolysis on fetal ductus arteriosus constriction with advancing gestational age. Am J Obstet Gynecol 1997;177:256-9; discussion 259-61.

15. Momma $\mathrm{K}$, Toyono $\mathrm{M}$. The role of nitric oxide in dilating the fetal ductus arteriosus in rats. Pediatr Res 1999;46:311-5.

16. Momma K, Takao A. Transplacental cardiovascular effects of four popular analgesics in rats. Am J Obstet Gynecol 1990;162:1304-10.

17. Bouayad A, Bernier SG, Asselin P, et al. Characterization of PGE2 receptors in fetal and newborn ductus arteriosus in the pig. Semin Perinatol 2001;25:70-5.

18. Guerguerian AM, Hardy P, Bhattacharya M, et al. Expression of cyclooxygenases in ductus arteriosus of fetal and newborn pigs. Am J Obstet Gynecol 1998;179(6 Pt 1):1618-26.
19. Ali I, Ryan CA. Transient renal failure in twins with maternal Cox-1/Cox-2 use in pregnancy. Ir Med J 2005;98:249-50.

20. King J, Flenady V, Cole S, Thornton S. Cyclo-oxygenase (COX) inhibitors for treating preterm labour. Cochrane Database Syst Rev 2005;2: CD001992.

21. El-Khuffash AF, McNamara PJ. Neonatologist-performed functional echocardiography in the neonatal intensive care unit. Semin Fetal Neonatal Med 2011;16:50-60.

22. Liu T, Laidlaw TM, Feng C, et al. Prostaglandin E2 deficiency uncovers a dominant role for thromboxane A2 in house dust mite-induced allergic pulmonary inflammation. Proc Natl Acad Sci USA 2012;109:12692-7.

23. Morrow JD, Roberts LJ 2nd. Mass spectrometric quantification of F2-isoprostanes in biological fluids and tissues as measure of oxidant stress. Methods Enzymol 1999;300:3-12.

24. Murali G, Milne GL, Webb CD, et al. Fish oil and indomethacin in combination potently reduce dyslipidemia and hepatic steatosis in $\operatorname{LDLR}(-/-)$ mice. J Lipid Res 2012;53:2186-97.

25. Hoggatt J, Mohammad KS, Singh P, et al. Differential stem- and progenitorcell trafficking by prostaglandin E2. Nature 2013;495:365-9. 